\title{
Asparagine Enhances Starch Accumulation in Developing and Germinating Lupin Seeds
}

\author{
Sławomir Borek • Agnieszka Galor • \\ Ewelina Paluch
}

Received: 3 May 2012/ Accepted: 7 November 2012/Published online: 16 January 2013

(c) The Author(s) 2013. This article is published with open access at Springerlink.com

\begin{abstract}
Regulation of starch accumulation in yellow (Lupinus luteus L.), white (L. albus L.), and Andean lupin (L. mutabilis Sweet) developing and germinating seeds was investigated. Research was conducted on cotyledons isolated from developing seeds as well as on organs of germinating seeds, that is, isolated embryo axes, excised cotyledons, and seedling axes and cotyledons. All organs were cultured in vitro for $96 \mathrm{~h}$ in different carbon $(60 \mathrm{mM}$ sucrose) and nitrogen (35 mM asparagine or $35 \mathrm{mM}$ nitrate) conditions. Ultrastructure observation showed one common pattern of changes in the number and size of starch granules caused by sucrose, asparagine, and nitrate in both developing and germinating seeds. Sucrose increased the number and size of starch granules. Asparagine additionally increased starch accumulation (irrespective of sucrose nutrition) but nitrate had no effect on starch accumulation. Asparagine treatment resulted in a significant decrease in soluble sugar level in all organs of germinating lupin seeds of the three species investigated. The above-mentioned changes were most clearly visible in white lupin organs. In white lupin, starch granules were visible even in cells of sucrose-starved isolated embryo axes where advanced autophagy occurs. The importance of asparagine-increased starch content in the creation of a strong source-sink gradient in developing and germinating lupin seeds is discussed.
\end{abstract}

Keywords Legume - Nitrate - Nonstarch seeds . Source-sink $\cdot$ Sucrose $\cdot$ Ultrastructure

S. Borek $(\bowtie) \cdot$ A. Galor $\cdot$ E. Paluch

Department of Plant Physiology, Adam Mickiewicz University, ul. Umultowska 89, 61-614 Poznań, Poland

e-mail: borek@amu.edu.pl

\section{Introduction}

Mature and dry lupin seeds do not contain starch (Hedley 2001; Borek and others 2006, 2011; Duranti and others 2008). However, starch is transiently accumulated in developing lupin seeds (Pinheiro and others 2005; Borek and others 2009) and disappears during seed maturation. A very similar transient starch accumulation is also observed in developing Medicago truncatula (Djemel and others 2005), Brassica napus (Da Silva and others 1997), and Arabidopsis oil seeds (Hills 2004; Baud and others 2008). Carbohydrate content in mature lupin seeds is about $36.5 \%$ and the basic carbohydrates are oligosaccharides and fiber (Hedley 2001). In contrast to lupin seeds, starch content in mature pea seeds may reach $50 \%$ of dry matter (Gallardo and others 2008). The main storage compound in mature lupin seeds is protein, especially globulins called conglutins (Ratajczak and others 1999). Protein content in lupin seeds may reach up to $50 \%$ of dry matter (Borek and others 2012a), whereas lipid level in lupin seeds may vary from a few to about $20 \%$ (Borek and others 2009, 2012b).

The storage compounds in developing legume seeds accumulate mainly in cotyledons (Borisjuk and others 2003; Duranti and others 2008; Borek and others 2011). They are synthesized from sugars (mainly sucrose) and amino acids (mainly glutamine and asparagine) provided by the mother plant to the embryos (Weber and others 2005; Allen and others 2009). Asparagine is the main form of transported nitrogen in many legume plants. In developing soybean seeds, asparagine content may reach $33-49 \%$ of the free amino acid pool and may be a determinant of storage protein content. The positive correlation between asparagine and storage protein content has been confirmed in soybean seeds (Hernández-Sebastià and others 2005). Asparagine stimulates synthesis of polypeptides in 
developing yellow lupin seeds as well (Ratajczak and others 1988, 1996). The elevation of storage protein accumulation by asparagine in developing lupin seeds simultaneously causes a decrease in storage lipid content (Borek and others 2009). The strong negative relationship between storage protein and lipid accumulation is typical for legume seeds and has been confirmed many times, especially in soybean seeds (Wilcox and Shibles 2001; Chung and others 2003; Hernández-Sebastià and others 2005). Asparagine also plays a crucial role during lupin seed germination. The main respiratory substrates in tissues of germinating lupin seeds are amino acids which can result in the generation of large quantities of ammonia. Because ammonia is toxic, it is accumulated in asparagine. The level of this amino acid during yellow lupin seed germination may reach up to $33 \%$ of organ dry matter. Moreover, during lupin symbiosis with Rhizobium, the assimilated dinitrogen is provided to the plant as asparagine (Lehmann and Ratajczak 2008).

Contrary to asparagine, nitrate is not a favorable nitrogen source for developing lupin seeds. Generally, nitrate does not affect storage globulin synthesis and accumulation in yellow lupin (Ratajczak and others 1988, 1996). In white lupin, nitrate has a negative effect on seed yield, globulin accumulation, total nitrogen (Ciesiołka and others 2008), and total carbohydrate (Ciesiołka and others 2005) content in seeds. However, the albumin level in white lupin seeds can be elevated by nitrate (Ciesiołka and others 2008). Experiments conducted on yellow, white, and Andean lupin developing cotyledons have shown that nitrate has a positive effect on protein and lipid level (Borek and others 2009).

Sucrose has dual functions in plant tissues. First, it is a nutrient sugar and carbon transport form. Second, it is an important regulatory agent that controls plant metabolism through regulation of gene expression. The regulatory function of sucrose and glucose has been studied extensively for many years and has been described in detail in many review papers (for example, Smeekens and others 2010). Sucrose regulates lupin seed metabolism as well. It has been shown that sucrose enhances protein and lipid accumulation in developing lupin cotyledons (Borek and others 2009). Sucrose inhibits seedling growth, but growth of isolated embryo axes is stimulated (Borek and others 2012a). Sucrose controls mobilization of storage protein during lupin seed germination. Carbohydrate deficiency in tissues enhances storage protein breakdown (Borek and others 2006) and stimulates the activity of proteases (Borek and Ratajczak 2002), glutamate dehydrogenase (Lehmann and Ratajczak 2008; Borek and others 2012a), and asparagine synthetase (Lehmann and Ratajczak 2008) or the activity of enzymes involved in arginine catabolism (Borek and others 2001). Sucrose also controls breakdown of storage lipid during lupin seed germination (Borek and Nuc 2011; Borek and others 2012b). The regulatory function of sucrose in starch metabolism in developing and germinating lupin seeds is not well understood. Up to now it was known only that sucrose increases starch content in embryo axes and cotyledons of germinating yellow lupin seeds (Borek and others 2006).

Because lupin seeds are protein-rich seeds, the majority of research is related to metabolism of this storage compound. Data concerning starch metabolism in lupin seeds is vestigial. In this article, research on the regulatory function of sucrose, asparagine, and nitrate in starch metabolism in developing and germinating lupin seeds is described. Experiments were conducted on three lupin species that differ significantly in the chemical composition of seed storage reserves. Seeds of yellow lupin contain about $45 \%$ of storage protein and only about $6 \%$ of storage lipid. Opposite to yellow lupin seeds are Andean lupin seeds which contain similar amounts of storage protein (40-50 \%) but the storage lipid level is considerably higher and reaches about $20 \%$. White lupin seeds contain the lowest amount of storage protein (up to $38 \%$ ), whereas the amount of lipid is intermediate (7-14\%) (Borek and others 2012a, b). The current research addresses two main questions. First, how do asparagine and nitrate (organic and inorganic nitrogen forms, respectively) regulate starch content in developing and germinating lupin seeds, and, second, is this regulation dependent on the content of other storage compounds in lupin seeds? Ultrastructural observations of starch granules in sink organs of developing (cotyledons) and germinating (embryo axes) yellow, white, and Andean lupin seeds cultured in vitro in different carbon (sucrose) and nitrogen (asparagine or nitrate) nutrition were performed. Also, starch and soluble sugar contents were determined in embryo axes and cotyledons of germinating yellow, white, and Andean lupin seeds cultured in vitro in different carbon and nitrogen conditions.

\section{Materials and Methods}

\section{Plant Material}

\section{Developing Seeds}

Plants of yellow lupin (Lupinus luteus L.) cv. Juno, white lupin (L. albus L.) cv. Butan, and Andean lupin (L. mutabilis Sweet) were grown on experimental fields of the Plant Breeding Station Smolice Division in Przebędowo (Poland) in two subsequent growing seasons. According to morphological and cytological classifications, five stages (denoted as I-V) can be distinguished during lupin seed development (Woźny and others 1984; Ratajczak 1986; 
Borek and others 2009). Briefly, in stages I and II, endosperm is present in liquid form (stage I) or in the form of a gelatinous lump (stage II). In stage III, seeds are light green, the endosperm disappears, and a dark green embryo fills the entire interior of the seed. In stage IV, seeds are at their biggest, the embryo is a little less green than in the preceding stage, and the embryo axis is beginning to turn yellow. Small pronounced brown spots appear on the seed coat (except for white lupin seeds). In stage V, seeds are desiccated, the embryo axis is yellow, and cotyledons are light green/yellow. Brown spots (mottling) are clearly visible on the yellow and Andean lupin seed coat. For the experiments described in this article, pods containing seeds at developmental stage III were collected. In this stage, starch granules are clearly visible in cotyledons and storage protein is accumulated at a low level, but the storage lipid content represents $45-50 \%$ of the maximal level of that observed in mature, dry seeds (Borek and others 2009). Developing pods were collected from experimental fields and were surface-sterilized by a 30-s immersion in $96 \%$ $(\mathrm{v} / \mathrm{v})$ ethanol and $20 \mathrm{~min}$ in $0.2 \% \mathrm{HgCl}_{2}$. Pods were finally washed five times with sterile distilled water. Seeds at developmental stage III were isolated from the pods. Next, cotyledons were separated from embryo axes and used for ultrastructure observations and for in vitro culture preparation. Excised cotyledons were placed in $10-\mathrm{cm}$ Petri dishes containing $11 \mathrm{ml}$ of Heller medium (Heller 1954) with $60 \mathrm{mM}$ sucrose $(+\mathrm{S})$ or without sucrose $(-\mathrm{S})$. Each medium was additionally enriched with $35 \mathrm{mM}$ asparagine (+Asn) or $35 \mathrm{mM} \mathrm{NaNO}_{3}\left(+\mathrm{NO}_{3}{ }^{-}\right)$. Asparagine solutions were sterilized through $0.22 \mu \mathrm{m}$ Millipore filters before being added to autoclaved media. The cotyledon in vitro cultures were maintained at a stable temperature of $25^{\circ} \mathrm{C}$ and a constant illumination of $75 \mu \mathrm{M}$ light quantum $\mathrm{m}^{-2} \mathrm{~s}^{-1}$. After $96 \mathrm{~h}$ of culture, cotyledons were used for ultrastructure observations.

\section{Mature and Germinating Seeds}

Yellow, white, and Andean lupin mature, dry seeds were surface-sterilized in $0.02 \% \mathrm{HgCl}_{2}$ for 10,15 , and $20 \mathrm{~min}$, respectively, washed five times with sterile, distilled water, and allowed to imbibe in the dark for $24 \mathrm{~h}$ at $25^{\circ} \mathrm{C}$. Embryo axes and cotyledons isolated from imbibed seeds, as well as whole imbibed seeds with their coats removed, were placed on sterilized filter paper (Whatman No. 3) in sterile tubes above Heller medium (Heller 1954) with $60 \mathrm{mM}$ sucrose $(+\mathrm{S})$ and without sucrose $(-S)$. Each medium was additionally enriched with $35 \mathrm{mM}$ asparagine $\left(+\right.$ Asn) or $35 \mathrm{mM} \mathrm{NaNO}_{3}\left(+\mathrm{NO}_{3}{ }^{-}\right)$. Asparagine solutions were sterilized by passing them through $0.22-\mu \mathrm{m}$ Millipore filters before being added to autoclaved media. Isolated embryo axes, excised cotyledons, and seedlings were cultured in vitro for $96 \mathrm{~h}$ in the dark at $25^{\circ} \mathrm{C}$.

\section{Preparation of Tissues for Transmission Electron Microscopy (TEM)}

Ultrastructure observations were conducted in parenchyma cells of the central part of developing cotyledons isolated from seeds at developmental stage III and in developing cotyledons cultured in vitro for $96 \mathrm{~h}$ in different carbon and nitrogen nutrition regimes. Among organs of germinating seeds, the ultrastructure of the root meristematic zone of cultured in vitro isolated embryo axes was investigated. Tissues were prepared according to Borek and others (2006). Tissue samples were fixed in a mixture of $4 \%$ glutaraldehyde and $4 \%$ paraformaldehyde $(1 / 1 \mathrm{v} / \mathrm{v})$, postfixed in $1 \%$ $\mathrm{OsO}_{4}$, and stained in $2 \%$ uranyl acetate. Low-viscosity Spurr's (1969) epoxy resin was used. Ultrathin sections were prepared using Ultracut S (Raichert), stained in $5 \%$ uranyl acetate and $0.5 \%$ lead citrate, and observed under the transmission electron microscope TEM-1200 Ex (JEOL).

\section{Determination of Soluble Sugars and Starch}

Carbohydrate content was measured in embryo axes and cotyledons of dry and imbibed seeds as well as in isolated embryo axes, excised cotyledons, and seedling axes and cotyledons cultured in vitro for $96 \mathrm{~h}$. The method of Oleksyn and others (1997) adapted to lupin tissues and described in detail by Borek and others (2006) was used. Briefly, soluble sugars were extracted three times from dried and powdered plant samples $(20 \mathrm{mg})$ with a mixture of methanol, chloroform, and water $(60 / 25 / 15 \mathrm{v} / \mathrm{v} / \mathrm{v})$. Concentration of soluble sugars were determined at $\lambda=625 \mathrm{~nm}$ using anthrone as reagent. Soluble sugar content was read from a standard curve made for glucose solutions $\left(40-280 \mathrm{mg} \mathrm{l}^{-1}\right)$. Starch content was also measured in the above-mentioned samples after soluble sugar extraction and was expressed as glucose concentration after starch hydrolysis by amylglucosidase from Aspergillus niger (Sigma-Aldrich). Concentration of glucose in starch hydrolyzates was measured at $\lambda=450$ using GAGO-20 kit (Sigma-Aldrich). Glucose content was determined from the standard curve made for glucose solutions (40-280 $\mathrm{mg} \mathrm{l}^{-1}$ ).

\section{Statistical Analysis}

Ultrastructural observations of developing cotyledons were performed in two subsequent growing seasons. Ultrastructure of isolated embryo axes was repeated twice (two separate in vitro culture experiments). Data concerning soluble sugars and starch content are the means of two to 
three replicates $\pm \mathrm{SD}$. The results were subjected to ANOVA statistical analysis and Tukey's HSD multiplerange test by using Statistica 10.0 software (StatSoft, Inc., Tulsa, OK).

\section{Results}

Developing Seeds

Large and numerous starch granules were observed in the parenchyma cells of yellow, white, and Andean lupin cotyledons that were isolated from developing seeds in stage III (Fig. 1a, b, c, respectively). In each cell of yellow lupin cotyledons, several amyloplasts were visible and there were three to six small or large starch granules in each amyloplast (Fig. 1a). In cotyledons of white and Andean lupin, amyloplasts were as numerous as in yellow lupin but contained usually individual, large starch granules (Fig. 1b, c, respectively). In Andean lupin cotyledons, starch granules were less numerous and were the smallest (Fig. 1c) compared to yellow and white lupin (Fig. 1a, b, respectively).

Ultrastructure observations of yellow, white, and Andean lupin cotyledons cultured in vitro for $96 \mathrm{~h}$ in different carbon $(+/-\mathrm{S})$ and nitrogen $\left(+\right.$ Asn and $+\mathrm{NO}_{3}{ }^{-}$) conditions showed some common changes that were observed in all three investigated species. However, because the clearest ultrastructural changes were visible in white lupin cotyledons, electron micrographs for only this species are presented (Fig. 2a-f). In yellow and white lupin cotyledons cultured in vitro for $96 \mathrm{~h}$ on medium with sucrose $(+\mathrm{S})$, a slight decrease in the size of starch granules, compared to cotyledons isolated from developing seeds, was observed. In Andean lupin, the decrease in size was larger. In all three lupin species, a lack of sucrose in the medium $(-S)$ caused an additional decrease in the number and size of starch granules compared to cotyledons fed with sucrose $(+\mathrm{S})$ (white lupin, Fig. 2a-f). Starch granules almost completely disappeared in cotyledons of yellow and Andean lupin cultured in $-\mathrm{S}$ media, irrespective of nitrogen (+Asn and $+\mathrm{NO}_{3}{ }^{-}$) nutrition. Asparagine added to the media $(+\mathrm{S}+\mathrm{Asn}$ and $-\mathrm{S}+\mathrm{Asn})$ caused a clear increase (compared to $+\mathrm{S}$ and $-\mathrm{S}$ cotyledons) in the number and size of starch granules in white lupin cotyledons (Fig. 2b, e). In yellow lupin cotyledons, this change was observed only in $+\mathrm{S}$ cotyledons. In yellow lupin cotyledons fed with sucrose and asparagine $(+\mathrm{S}+$ Asn $)$, the number and size of starch granules were similar to those observed in cotyledons used for preparation of in vitro culture, whereas in white lupin cotyledons they were slightly higher (white lupin, compare Figs. 2b, 1b). In Andean lupin cotyledons, asparagine did not affect the
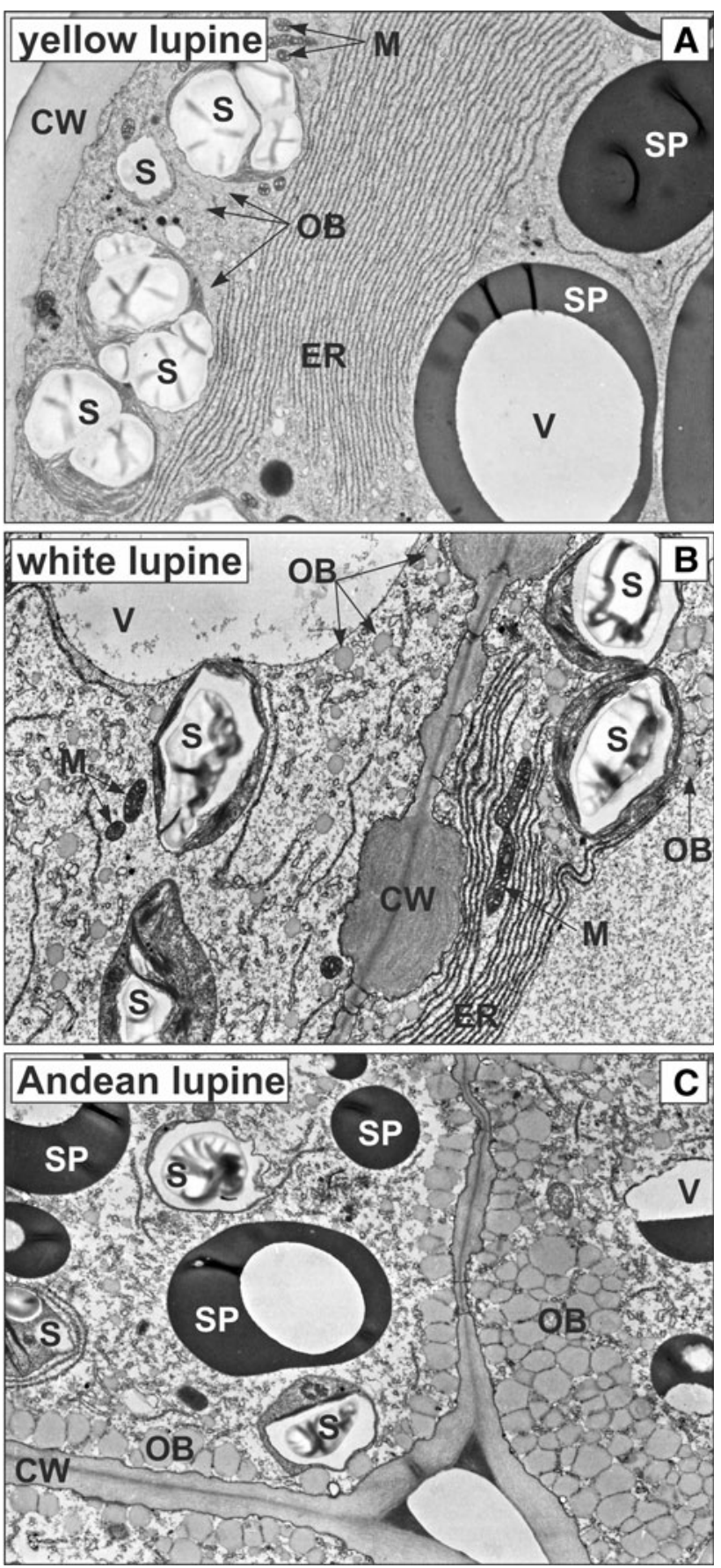

Fig. 1 Electron micrographs of yellow (a), white (b), and Andean lupin (c) cotyledons isolated from seeds at developmental stage III. $C W$ cell wall, $E R$ endoplasmic reticulum, $M$ mitochondrion, $O B$ oil body, $S$ starch, $S P$ storage protein, $V$ vacuole. Magnification of each image is $\times 5,000$

number and size of starch granules irrespective of carbon $(+/-S)$ nutrition. The number and size of starch granules in $+\mathrm{S}+$ Asn and $-\mathrm{S}+$ Asn Andean lupin cotyledons were similar to $+\mathrm{S}$ and $-\mathrm{S}$ cotyledons, respectively. In all three lupin species, nitrate $\left(+\mathrm{NO}_{3}{ }^{-}\right)$added to the $+\mathrm{S}$ and $-\mathrm{S}$ 
media did not cause any changes in the number and size of starch granules. Ultrastructural observations of starch granules in $+\mathrm{S}+\mathrm{NO}_{3}{ }^{-}$and $-\mathrm{S}+\mathrm{NO}_{3}{ }^{-}$cotyledons (white lupin, Fig. 2c, f) were very similar to those in $+S$ and $-S$ cotyledons (white lupin, Fig. 2a, d), respectively.

\section{Mature and Germinating Seeds}

The ultrastructure of embryo axes and cotyledons of dry and imbibed yellow, white, and Andean lupin seeds has been previously described in detail by Borek and others
(2011), who showed that starch does not occur in the organs of dry lupin seeds. In the current study, the ultrastructure of root meristematic zone cells of yellow, white, and Andean lupin embryo axes cultured in vitro for $96 \mathrm{~h}$ in different carbon $(+/-\mathrm{S})$ and nitrogen $\left(+\mathrm{Asn}\right.$ and $\left.+\mathrm{NO}_{3}{ }^{-}\right)$ conditions is presented. The clearest changes in the number and size of starch granules caused by carbon and nitrogen nutrition were visible only in white lupin organs, so electron micrographs only for this species (Fig. 2a-f) are presented. Among the three investigated lupin species, starch granules were visible only in white lupin root meristematic
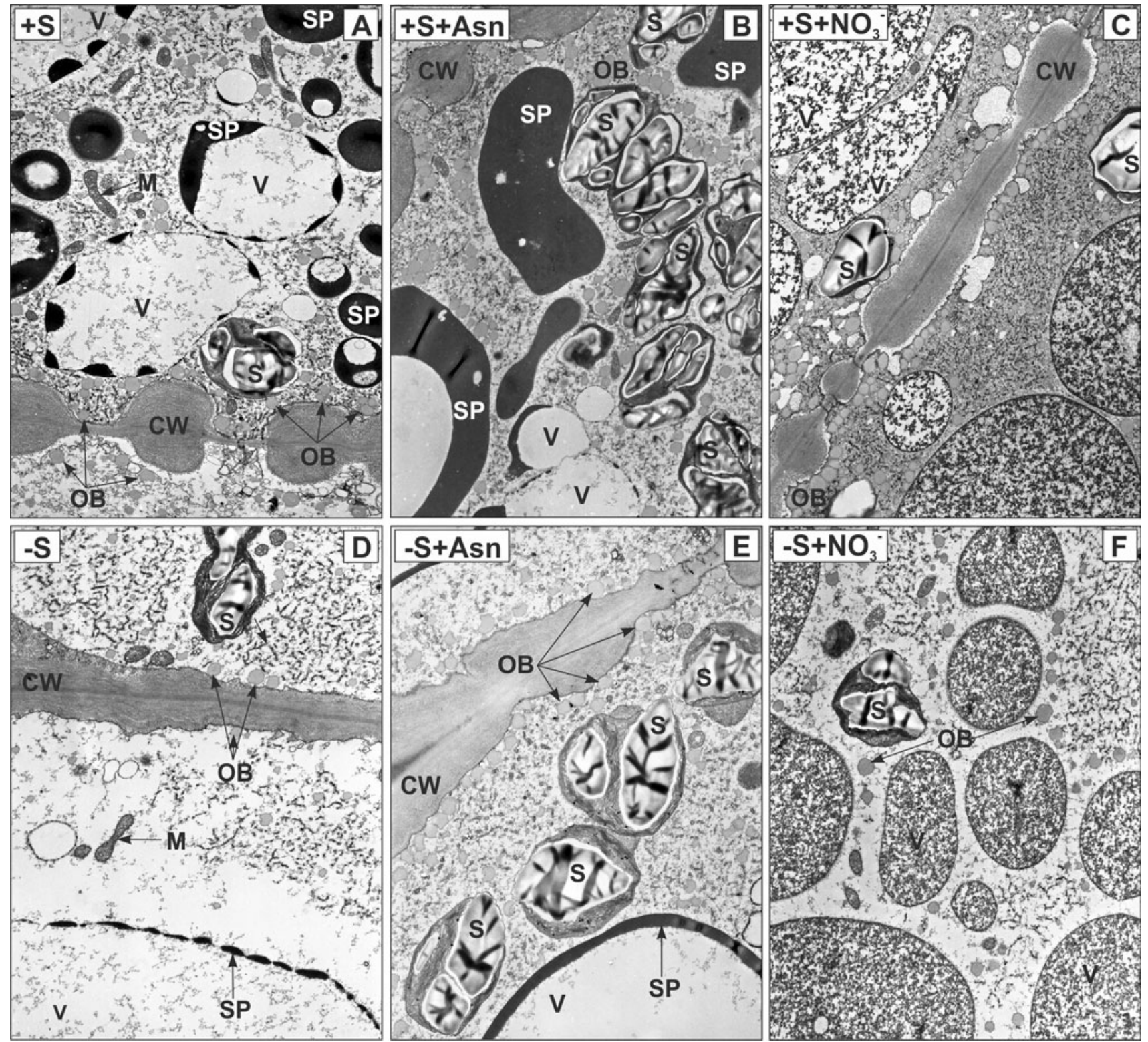

Fig. 2 Electron micrographs of white lupin cotyledons isolated from seeds at developmental stage III and cultured in vitro for $96 \mathrm{~h}$ on medium with $60 \mathrm{mM}$ sucrose $(\mathbf{a}, \mathbf{b}, \mathbf{c},+\mathrm{S})$ or without sucrose $(\mathbf{d}, \mathbf{e}, \mathbf{f}$, $-\mathrm{S})$. Media were additionally enriched with $35 \mathrm{mM}$ asparagine (b, e,
+Asn) or $35 \mathrm{mM}$ nitrate $\left(\mathbf{c}, \mathbf{f},+\mathrm{NO}_{3}{ }^{-}\right) . \mathrm{CW}$ cell wall, $M$ mitochondrion, $O B$ oil body, $S$ starch, $S P$ storage protein, $V$ vacuole. Magnification of each image is $\times 5,000$ 
zone cells of isolated embryo axes cultured in vitro on medium with sucrose $(+S)$ and without sucrose $(-S)$ (Fig. 3a, d). In the same cells of yellow and Andean lupin isolated embryo axes, starch granules were visible only in $+\mathrm{S}$ organs and were very small and sparse. In yellow and Andean lupin $-\mathrm{S}$ isolated embryo axes, starch was not observed at all. In white lupin isolated embryo axes, sucrose added to the medium $(+\mathrm{S})$ significantly increased the number and size of starch granules (Fig. 3a-c) compared to sucrose-starved (-S) axes (Fig. 3d-f), and this effect was observed irrespective of nitrogen nutrition $\left(+\right.$ Asn and $\left.+\mathrm{NO}_{3}{ }^{-}\right)$. Asparagine caused a clear increase in the number and size of starch granules in white lupin isolated embryo axes. This increase was observed in both $+\mathrm{S}$ and $-\mathrm{S}$ axes (Fig. 3a, b, d, e, respectively). Similar to developing cotyledons, in root meristematic zone cells of isolated embryo axes of all three lupin species, nitrate $\left(+\mathrm{NO}_{3}{ }^{-}\right)$did not cause any changes in the number and size of starch granules (white lupin, Fig. 3a, c, d, f).

Spectrophotometric determination of soluble sugars and starch content in embryo axes and cotyledons of dry and imbibed seeds, as well as in organs cultured in vitro for
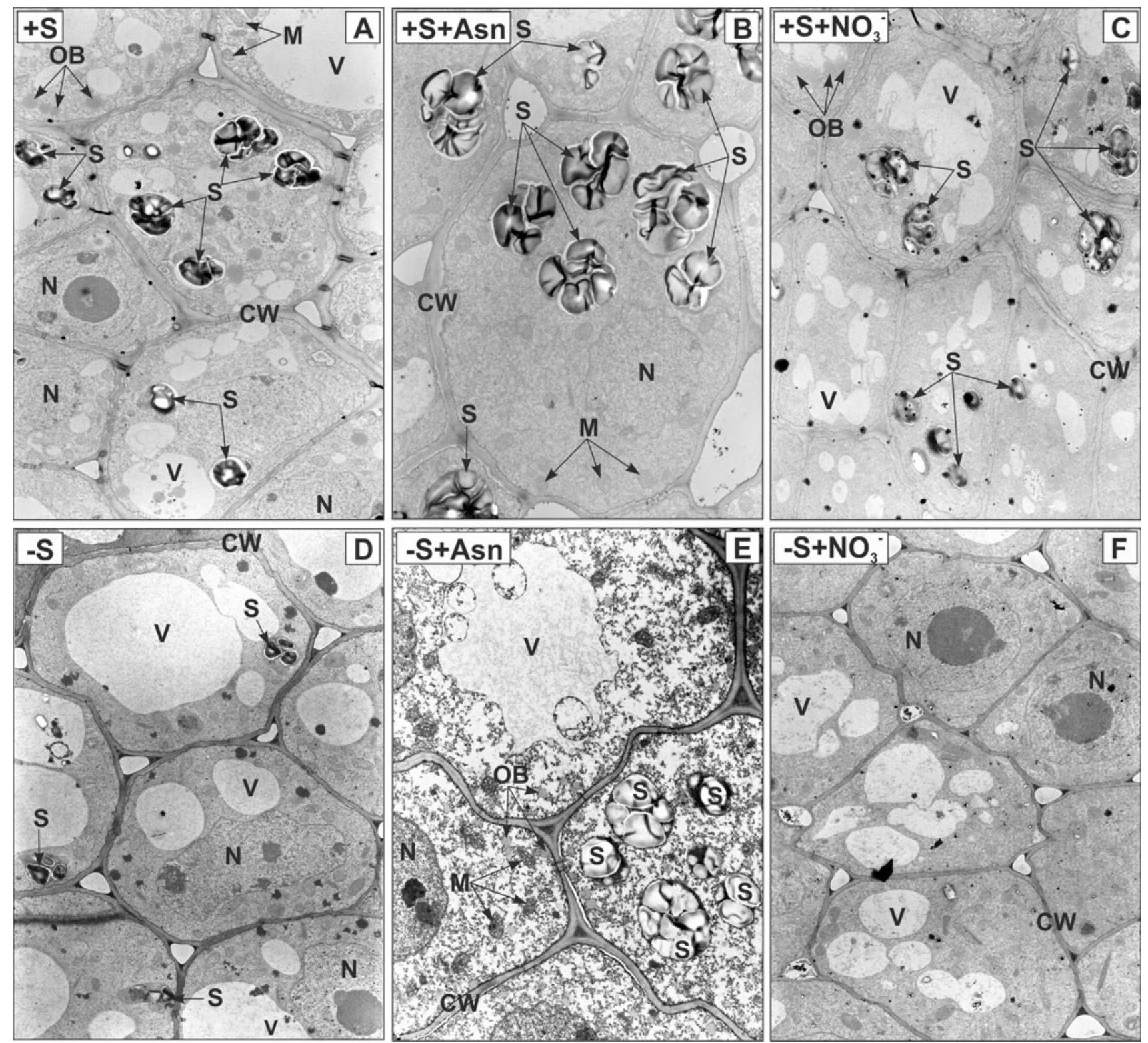

Fig. 3 Electron micrographs of meristematic zone cells of white lupin embryo axes isolated from imbibed seeds $(24 \mathrm{~h})$ and cultured in vitro for $96 \mathrm{~h}$ on medium with $60 \mathrm{mM}$ sucrose $(\mathbf{a}, \mathbf{b}, \mathbf{c},+\mathrm{S})$ or without sucrose $(\mathbf{d}, \mathbf{e}, \mathbf{f},-\mathrm{S})$. Media were additionally enriched with

$35 \mathrm{mM}$ asparagine $(\mathbf{b}, \mathbf{e},+$ Asn $)$ or $35 \mathrm{mM}$ nitrate $\left(\mathbf{c}, \mathbf{f},+\mathrm{NO}_{3}{ }^{-}\right) . \mathrm{CW}$ cell wall, $M$ mitochondrion, $N$ nucleus, $O B$ oil body, $S$ starch, $V$ vacuole. Magnification of each image is $\times 4,000$ 
$96 \mathrm{~h}$ in different carbon $(+/-\mathrm{S})$ and nitrogen $(+$ Asn and $+\mathrm{NO}_{3}{ }^{-}$) nutrition, showed one pattern of carbohydrate change in tissues of all three investigated lupin species. During seed imbibition $(24 \mathrm{~h})$, the soluble sugar level in embryo axes was significantly decreased (Figs. 4, 5, 6a). In cotyledons, only a slight but not statistically significant increase was observed (Figs. 4, 5, 6c). Starch content in embryo axes and cotyledons of dry seeds was very low (Figs. 4, 5, 6b, d) but a large increase in starch content in axes during $24 \mathrm{~h}$ of imbibition was observed (Figs. 4, 5, 6b). This increase in yellow lupin embryo axes was about 21-fold, in white lupin about 24-fold, and in Andean lupin about 11-fold. In each of the investigated organs cultured in vitro for $96 \mathrm{~h}$ on medium without sucrose $(-\mathrm{S})$, soluble sugar content was significantly lower than in organs fed with sucrose $(+\mathrm{S})$ (Figs. 4, 5, 6a, c). The decrease in starch content was observed as well, but the differences were not always statistically significant (Figs. 4, 5, 6b, d). In each of the investigated organs, asparagine caused a decrease in soluble carbohydrate level and simultaneously increased starch content. This was observed in organs fed $(+\mathrm{S})$ and not fed $(-S)$ with sucrose (Figs. 4, 5, 6a, b, c, d). The clearest lowering of soluble sugar level by asparagine occurred in
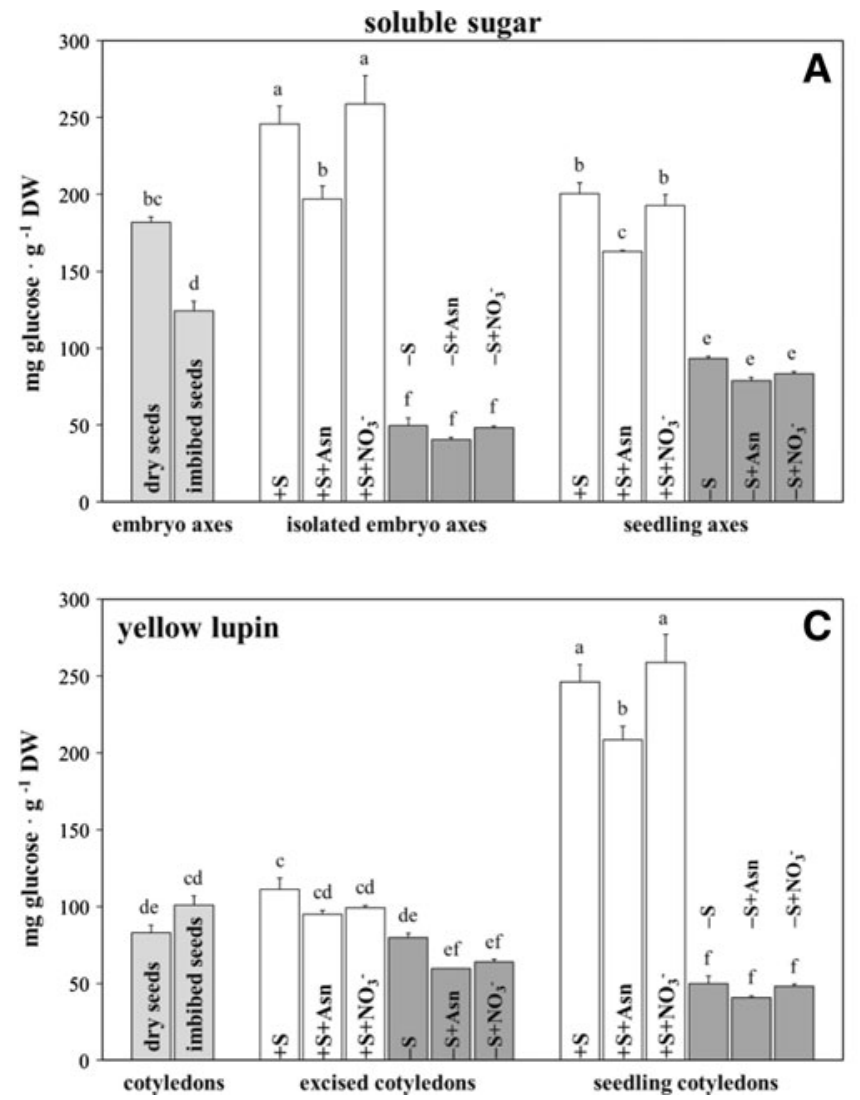

Fig. 4 Soluble sugar $(\mathbf{a}, \mathbf{c})$ and starch $(\mathbf{b}, \mathbf{d})$ content in axes $(\mathbf{a}, \mathbf{b})$ and cotyledons $(\mathbf{c}, \mathbf{d})$ of yellow lupin dry and imbibed seeds and in axes and cotyledons cultured in vitro for $96 \mathrm{~h}$ on medium with $60 \mathrm{mM}$ sucrose $(+S)$ or without sucrose $(-S)$. Media were additionally isolated embryo axes, and in those organs the differences were always statistically significant. The most evident stimulatory effect of asparagine on starch accumulation was observed in excised cotyledons. The effect of nitrate $\left(+\mathrm{NO}_{3}{ }^{-}\right)$on soluble carbohydrate content was ambiguous. In some organs it caused a decrease (compared to $+\mathrm{S}$ or $-\mathrm{S}$ ) in carbohydrate content, for example, soluble sugar in white and Andean lupin isolated embryo axes $+\mathrm{S}+\mathrm{NO}_{3}{ }^{-}$(Figs. 5, 6 a, respectively) or starch in yellow lupin excised cotyledons $+\mathrm{S}+\mathrm{NO}_{3}{ }^{-}$(Fig. 4d). In others, the carbohydrate level was higher, for example, soluble sugars in Andean lupin seedling axes $+\mathrm{S}+\mathrm{NO}_{3}{ }^{-}$(Fig. 6a) or starch in white lupin excised cotyledons $-\mathrm{S}+\mathrm{NO}_{3}{ }^{-}$(Fig. 5d) and Andean lupin seedling cotyledons $+\mathrm{S}+\mathrm{NO}_{3}{ }^{-}$and $-\mathrm{S}+\mathrm{NO}_{3}{ }^{-}$ (Fig. 6d). In most of the other comparisons, the differences were not statistically significant (Figs. 4, 5, 6a-d).

\section{Discussion}

A strong negative relationship between storage protein and lipid accumulation occurs during soybean seed development (Wilcox and Shibles 2001; Chung and others 2003;
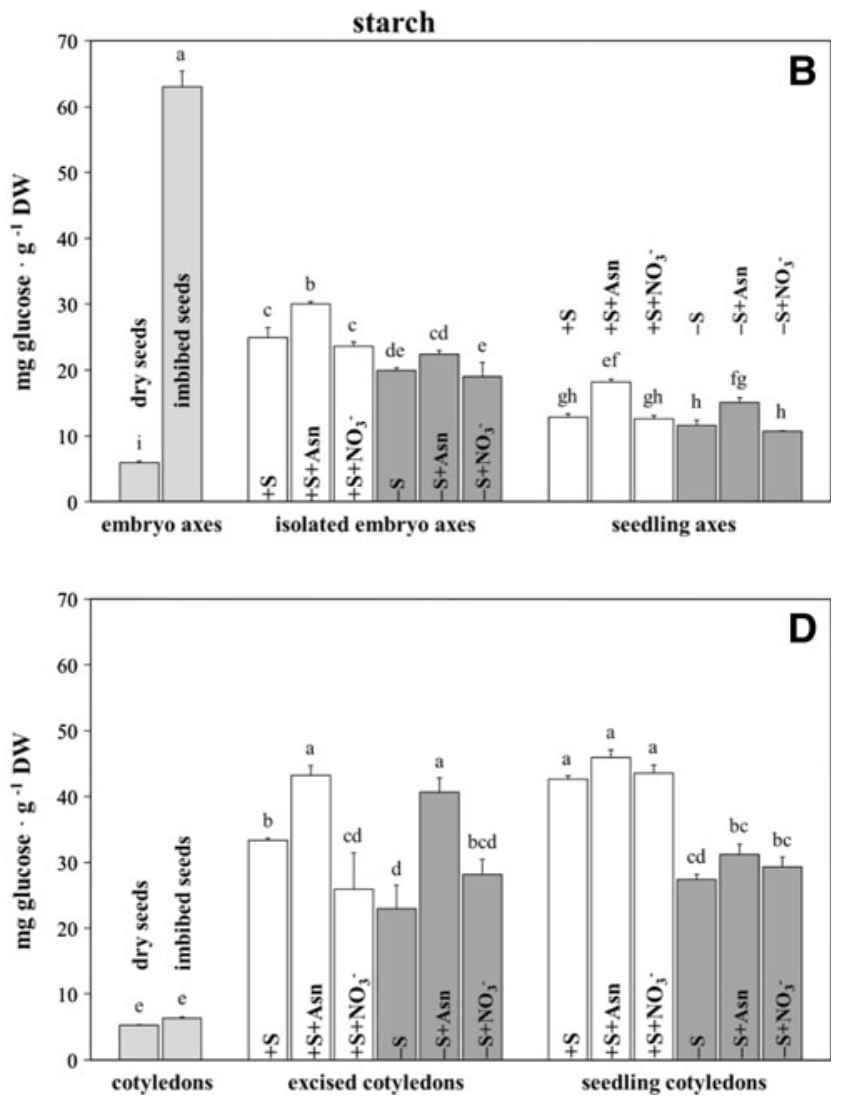

enriched with $35 \mathrm{mM}$ asparagine (+Asn) or $35 \mathrm{mM}$ nitrate $\left(+\mathrm{NO}_{3}{ }^{-}\right)$. Different letters above the error bars indicate statistically significant differences at $p \leq 0.05$ (ANOVA; Tukey's HSD multiple-range test) 

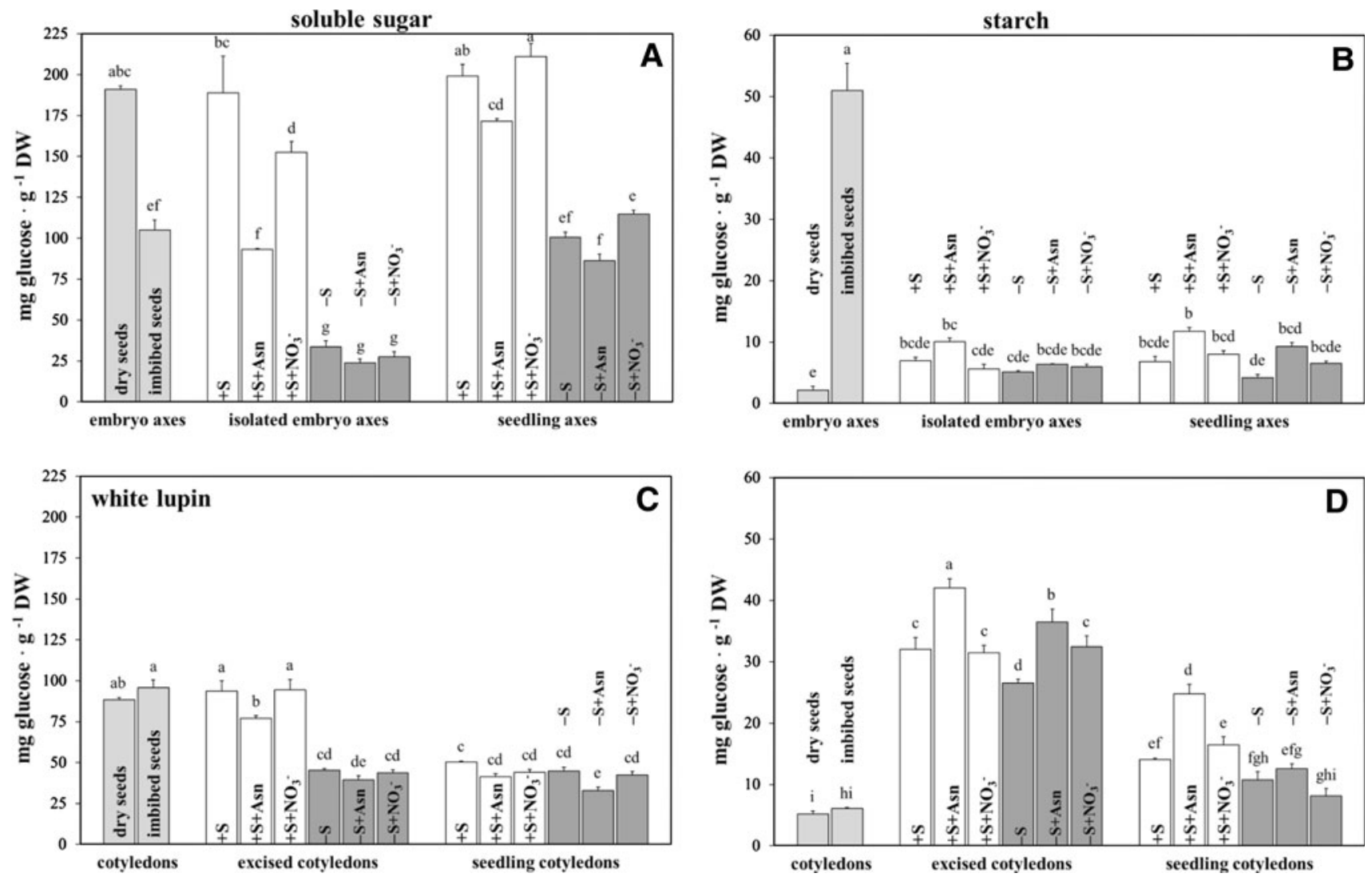

Fig. 5 Soluble sugar $(\mathbf{a}, \mathbf{c})$ and starch $(\mathbf{b}, \mathbf{d})$ content in axes $(\mathbf{a}, \mathbf{b})$ and cotyledons (c, d) of white lupin dry and imbibed seeds and in axes and cotyledons cultured in vitro for $96 \mathrm{~h}$ on medium with $60 \mathrm{mM}$ sucrose $(+S)$ or without sucrose $(-S)$. Media were additionally

Hernández-Sebastià and others 2005). Additional research also indicates an inverse relationship in the accumulation of storage protein and carbohydrates, especially sucrose (Wilcox and Shibles 2001). Our earlier research conducted on yellow, white, and Andean lupin developing cotyledons has shown that the negative relationship between protein and lipid accumulation exists in lupin seeds as well. The increase in protein content (caused by asparagine) was accompanied by a decrease in the lipid level. Simultaneously, it was shown that the positive relationship between protein and lipid accumulation in developing lupin cotyledons could also be possible. This positive effect was caused by nitrate which stimulated accumulation of both protein and lipid at the same time (Borek and others 2009). Ultrastructure observations presented in this article showed that nitrate had no effect on the number and size of starch granules in developing cotyledons of three investigated lupin species (white lupin, Fig. 2a, c, d, f). More interesting was the effect caused by asparagine. This amino acid caused an increase in the number and size of starch granules in yellow and white lupin developing cotyledons. In white lupin cotyledons fed with sucrose and asparagine

enriched with $35 \mathrm{mM}$ asparagine (+Asn) or $35 \mathrm{mM}$ nitrate $\left(+\mathrm{NO}_{3}{ }^{-}\right)$. Different letters above the error bars indicate statistically significant differences at $p \leq 0.05$ (ANOVA; Tukey's HSD multiple-range test)

(+S+Asn) (Fig. 2b), the number and size of starch granules was even higher than in the cotyledons used for in vitro culture preparation (Fig. 1b). This showed that in developing lupin seeds (at least white lupin), the positive relationship in accumulation of protein (Borek and others 2009) and starch (Fig. 2b) is possible. However, during seed maturation, starch is degraded. It is postulated that carbon skeletons from degraded starch are used for synthesis of other compounds during seed maturation (Gallardo and others 2008). It has been proposed that in oilseeds starch constitutes an important carbon source required to sustain lipid synthesis during the phase of rapid oil deposition (Baud and others 2008).

At the present stage of the research it is impossible to unambiguously explain the mechanism of the effect caused by asparagine. This is one of the key amino acids in lupin developing seeds. Asparagine is the main transport form of nitrogen in lupin plants (Lehmann and Ratajczak 2008) and one of the most abundant amino acids provided by the host plant to the developing soybean (Hernández-Sebastià and others 2005) and other legume seeds (Weber and others 2005). Asparagine as a substrate for storage protein 

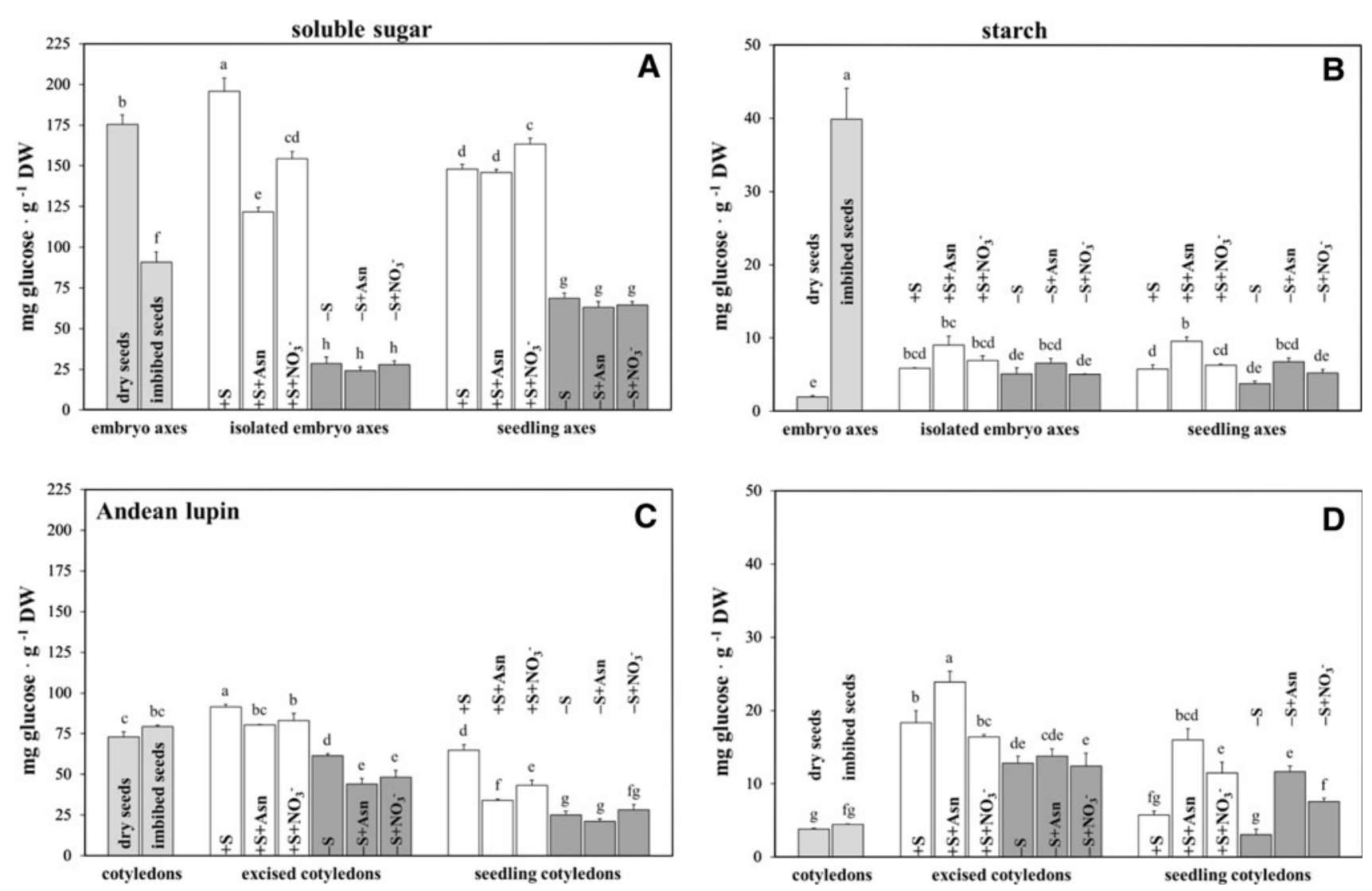

Fig. 6 Soluble sugar $(\mathbf{a}, \mathbf{c})$ and starch $(\mathbf{b}, \mathbf{d})$ content in axes $(\mathbf{a}, \mathbf{b})$ and cotyledons $(\mathbf{c}, \mathbf{d})$ of Andean lupin dry and imbibed seeds and in axes and cotyledons cultured in vitro for $96 \mathrm{~h}$ on medium with $60 \mathrm{mM}$ sucrose $(+\mathrm{S})$ or without sucrose $(-\mathrm{S})$. Media were additionally

synthesis increases the content of this storage compound in developing lupin seeds (Borek and others 2009). However, through stimulation of starch accumulation, the sink strength is probably improved because the increase in starch accumulation causes a decrease in soluble sugar levels (Figs. 4, 5, 6a, b, c d). Although this relationship has been tested only in germinating lupin seeds, it is highly probable that such a relationship exists in developing lupin seeds. The similar, inverse relationship in soluble sugars and starch content has been confirmed in developing Vicia faba seeds (Weber and others 2005). The decrease in soluble carbohydrate content in sink tissues of developing seeds enhances carbon flow from the mother plant. It has been proven that in developing faba bean seeds fed with high concentrations of sugars, suppression of VfSUT7 (sucrose transporter) expression occurs (Weber and others 1997). Asparagine (as well as glutamine) provided by the mother plant to the developing embryo is converted to other amino acids prior to storage protein synthesis. Conversion of the amide amino acids to the other amino acids demands carbon skeletons derived from sucrose imported from the phloem (Hernández-Sebastià and others 2005).

enriched with $35 \mathrm{mM}$ asparagine (+Asn) or $35 \mathrm{mM}$ nitrate $\left(+\mathrm{NO}_{3}{ }^{-}\right)$. Different letters above the error bars indicate statistically significant differences at $p \leq 0.05$ (ANOVA; Tukey's HSD multiple-range test)

Sucrose is also the main substrate for lipid synthesis in developing seeds (Baud and others 2008; Baud and Lepiniec 2010). However, in developing lupin seeds, asparagine causes a significant decrease in storage lipid accumulation (Borek and others 2009). In such circumstances, in the developing embryo, an oversupply of sucrose could occur and sink strength could decrease. Sucrose and other soluble sugars could be transiently managed by starch accumulation. The importance of transiently accumulated starch in the establishment of the embryo as a sink organ prior to the onset of oil deposition was also emphasized in developing B. napus embryos (Da Silva and others 1997; Baud and others 2008).

As already mentioned, starch that has accumulated during seed development is degraded during seed maturation and finally disappears. As a consequence, starch does not exist in mature and dry lupin seeds (Hedley 2001; Borek and others 2006; Duranti and others 2008; Borek and others 2011). This statement is based on ultrastructure observations (Borek and others 2006, 2011). Spectrophotometric determination of starch content in dry lupin seeds showed that this polysaccharide occurs at a very low level 
in embryo axes and cotyledons of lupin dry seeds (Fig. 4, 5, 6b, d, dry seeds). During seed imbibition, a huge increase in starch content was noted. This rapid increase was observed in embryo axes but not in cotyledons (Figs. 4, 5, 6b, d, imbibed seeds). An increase in embryo axis sink strength could be a critical factor during seed imbibition and germination. The increase in starch content in imbibed embryo axes coincided with a significant decrease in soluble sugar level (Figs. 4, 5, 6a). No significant changes in soluble sugar levels were observed in cotyledons of imbibed seeds (Figs. 4, 5, 6c). Such rapid decreases in soluble sugar levels in axes may enhance carbon flow from cotyledons.

Similar to the ultrastructure analysis of developing cotyledons, the ultrastructure of isolated embryo axes cultured in vitro showed that white lupin was unique among the three investigated lupin species. Two of the clearest examples of this uniqueness are the number and size of starch granules caused by sucrose and asparagine and the occurrence of starch granules even in sucrosestarved ( $-\mathrm{S}$ ) isolated embryo axes (Fig. 3d, e). However, it should be remembered that ultrastructure observations were conducted on a small part of the root, that is, in root meristematic zone cells of isolated embryo axes. Those organs and this zone were selected based on our previous research related to the regulatory function of sucrose in the metabolism of germinating lupin seeds. Changes caused by sucrose in the ultrastructure of the root meristematic zone of isolated embryo axes were distinctive (in deposits of storage protein, oil bodies, starch granules, or cell vacuolization) (Borek and others 2006, 2011). The changes in the same zone of seedling roots were not as spectacular as those in isolated embryo axes (Borek and others 2006, 2012a). In yellow, white, and Andean lupin isolated embryo axes cultured in vitro, it was noted that the number and size of starch granules were clearly higher in the organs fed with sucrose (Borek and others 2011; Fig. 3a, d). The effect of nitrogen nutrition (+Asn and $+\mathrm{NO}_{3}{ }^{-}$) on starch granules at the ultrastructural level was visible only in white lupin embryo axes (Fig. 3a-f) and it was the same as described above in developing cotyledons (Fig. 2a-f). Spectrophotometric determination (in which whole organs were used) of starch content showed that the effect caused by sucrose, asparagine, and nitrate was similar in isolated embryo axes and excised cotyledons as well as in seedling axes and cotyledons of all three investigated lupin species (Figs. 4, 5, 6a-f), and it was the same as that observed on the ultrastructure level in white lupin (Fig. 3a-f). The most interesting was asparagine treatment, which resulted in an enhanced starch content (Figs. 3a, b, 4, 5, 6b, d) and a simultaneous decrease in the soluble sugar level (Figs. 4, 5, $6 \mathrm{a}, \mathrm{c})$. This relationship was observed in organs cultured with and without sucrose.
At the present stage of the research, as in developing cotyledons, the mechanism of the stimulatory effect of asparagine on starch accumulation remains unknown. However, it is probable that starch accumulation is one of the ways soluble sugars are maintained at a low level in lupin tissues. The low level of soluble carbohydrates is extremely important in tissues of germinating seeds. It has been proven many times that sucrose and glucose control storage compound breakdown during germination. For example, during lupin seed germination, sucrose starvation significantly enhances storage protein mobilization (Borek and Ratajczak 2002; Borek and others 2011, 2012a). Amino acids liberated from storage proteins are used for synthesis of other compounds but are used also as respiratory substrates (Borek and others 2001; Morkunas and others 2003; Lehmann and Ratajczak 2008). Asparagine added to the medium may also inhibit the use of soluble carbohydrates as respiratory substrates and may also disturb the osmotic potential and source-sink gradient. The hypothesis that asparagine enhances starch synthesis thus allowing soluble sugars to be maintained at low levels was supported by spectrophotometric determination of carbohydrates (Figs. 4, 5, 6a, d) and is additionally supported by high starch content in white and Andean lupin excised cotyledons (Figs. 5, 6d, respectively). Starch content in excised cotyledons (irrespective of carbon and nitrogen nutrition) was significantly higher than starch content in seedling cotyledons (Figs. 5, 6d). In lupin excised and seedling cotyledons cultured in vitro for $96 \mathrm{~h}$, the mobilization of reserves is advanced (Borek and others 2002, 2006, 2011, 2012a, b). However, the exclusion of the export of reserve mobilization products from excised cotyledons to the growing axis resulted in significantly higher starch accumulation than in seedling cotyledons (Figs. 5, 6d).

It is worth mentioning that in white lupin isolated embryo axes starch granules were visible even in the cells of sucrose-starved $(-\mathrm{S})$ organs (Fig. 3d, e). This is puzzling because a significant increase in vacuolization in the same cells was observed (Fig. 3d, e; Borek and others 2011). This indicates advanced autophagy triggered in embryonic cells by sucrose starvation. In the same organs, a decrease in phosphatidylcholine content, which could be one of the autophagy markers, was also detected. This question has been discussed in more detail in our previous articles (Borek and others 2011, 2012b).

In summary, the data presented here and in our previous work (Borek and others 2006, 2009, 2011, 2012b) demonstrate that starch in tissues of yellow, white, and Andean lupin seeds is a temporary starch. Although starch occurs in developing seeds, it is not an important storage compound because lupin mature seeds do not contain starch. It is probable that the transient starch accumulation observed 
during lupin seed development and germination is important for maintaining the appropriate source-sink gradient and low levels of soluble sugars in tissues. The stimulatory effect of asparagine on starch synthesis in lupin seeds is interesting and requires further research. Finally, among the three investigated lupin species, white lupin is distinctive because the starch granules were visible in cells of sucrose-starved isolated embryo axes where advanced autophagy occurs.

Acknowledgments We thank Dr. Stanisław Stawinski, the Head of the Plant Breeding Station Smolice Division in Przebędowo, for providing yellow, white, and Andean lupin seeds. This work was supported by the National Science Centre (Grant No. NN310 003540).

Open Access This article is distributed under the terms of the Creative Commons Attribution License which permits any use, distribution, and reproduction in any medium, provided the original author(s) and the source are credited.

\section{References}

Allen DK, Ohlrogge JB, Shachar-Hill Y (2009) The role of light in soybean seed filling metabolism. Plant J 58:220-234

Baud S, Lepiniec L (2010) Physiological and developmental regulation of seed oil production. Prog Lipid Res 49:235-249

Baud S, Dubreucq B, Miquel M, Rochat C, Lepiniec L (2008) Storage reserve accumulation in Arabidopsis: metabolic and developmental control of seed filling. The Arabidopsis Book 6:e0113. Available at http://www.bioone.org/doi/full/10.1199/tab.0113. Accessed 24 July 2008

Borek S, Nuc K (2011) Sucrose controls storage lipid breakdown on gene expression level in germinating yellow lupine (Lupinus luteus L.) seeds. J Plant Physiol 168:1795-1803

Borek S, Ratajczak W (2002) Sugars as a metabolic regulator of storage protein mobilization in germinating seeds of yellow lupine (Lupinus luteus L.). Acta Physiol Plant 24:425-434

Borek S, Morkunas I, Ratajczak W, Ratajczak L (2001) Metabolism of amino acids in germinating yellow lupine seeds III. Breakdown of arginine in sugar-starved organs cultivated in vitro. Acta Physiol Plant 23:141-148

Borek S, Ratajczak W, Ratajczak L (2006) Ultrastructural and enzymatic research on the role of sucrose in mobilization of storage lipids in germinating yellow lupine seeds. Plant Sci 170:441-452

Borek S, Pukacka S, Michalski K, Ratajczak L (2009) Lipid and protein accumulation in developing seeds of three lupine species: Lupinus luteus L., Lupinus albus L., and Lupinus mutabilis Sweet. J Exp Bot 60:3453-3466

Borek S, Kubala S, Kubala S, Ratajczak L (2011) Comparative study of storage compound breakdown in germinating seeds of three lupine species. Acta Physiol Plant 33:1953-1968

Borek S, Kubala S, Kubala S (2012a) Regulation by sucrose of storage compounds breakdown in germinating seeds of yellow lupine (Lupinus luteus L.), white lupine (Lupinus albus L.) and Andean lupine (Lupinus mutabilis Sweet). I. Mobilization of storage protein. Acta Physiol Plant 34:701-711

Borek S, Pukacka S, Michalski K (2012b) Regulation by sucrose of storage compounds breakdown in germinating seeds of yellow lupine (Lupinus luteus L.), white lupine (Lupinus albus L.) and Andean lupine (Lupinus mutabilis Sweet). II. Mobilization of storage lipid. Acta Physiol Plant 34:1199-1206

Borisjuk L, Rolletschek H, Wobus U, Weber H (2003) Differentiation of legume cotyledons as related to metabolic gradients and assimilate transport into seeds. J Exp Bot 54:503-512

Chung J, Babka HL, Graef GL, Staswick PE, Lee DJ, Cregan PB, Shoemaker RC, Specht JE (2003) The seed protein, oil, and yield QTL on soybean linkage group I. Crop Sci 43:1053-1067

Ciesiołka D, Muzquiz M, Burbano C, Altares P, Pedrosa MM, Wysocki W, Folkman W, Popenda M, Gulewicz K (2005) An effect of various nitrogen forms used as fertilizer on Lupinus albus $\mathrm{L}$. yield and protein, alkaloid and $\alpha$-galactosides content. J Agron Crop Sci 191:458-463

Ciesiołka D, Aniszewski T, Wysocki W, Pilarski R, Gulewicz K (2008) Evaluation of the effect of various nitrogen forms on the Lupinus albus seed protein composition. Acta Soc Bot Pol 77:93-98

Da Silva PMFR, Eastmond PJ, Hill LM, Smith AM, Rawsthorne S (1997) Starch metabolism in developing embryos of oilseed rape. Planta 203:480-487

Djemel N, Guedon D, Lechevalier A, Salon C, Miquel M, Prosperi JM, Rochat C, Boutin JP (2005) Development and composition of the seeds of nine genotypes of the Medicago truncatula species complex. Plant Physiol Biochem 43:557-566

Duranti M, Consonni A, Magni C, Sessa F, Scarafoni A (2008) The major proteins of lupin seed: characterisation and molecular properties for use as functional and nutraceutical ingredients. Trends Food Sci Tech 19:624-633

Gallardo K, Thompson R, Burstin J (2008) Reserve accumulation in legume seeds. C R Biol 331:755-762

Hedley CL (2001) Grain legume carbohydrates. In: Hedley CL (ed) Carbohydrates in grain legume seeds: improving nutritional quality and agronomic characteristics. CAB International, Wallingford, pp 11-14

Heller R (1954) Recherches sur la nutrition minérale des tissus végétaux ciltivés in vitro. Ann Sci Nat Bot Biol Veg 14:1-223

Hernández-Sebastià C, Marsolais F, Saravitz C, Israel D, Dewey RE, Huber SC (2005) Free amino acid profiles suggest a possible role for asparagine in the control of storage-product accumulation in developing seeds of low- and high-protein soybean lines. J Exp Bot 56:1951-1963

Hills MJ (2004) Control of storage-product synthesis in seeds. Curr Opin Plant Biol 7:302-308

Lehmann T, Ratajczak L (2008) The pivotal role of glutamate dehydrogenase $(\mathrm{GDH})$ in the mobilization of $\mathrm{N}$ and $\mathrm{C}$ from storage material to asparagine in germinating seeds of yellow lupine. J Plant Physiol 165:149-158

Morkunas I, Garnczarska M, Bednarski W, Ratajczak W, Waplak S (2003) Metabolic and ultrastructural responses of lupine embryo axes to sugar starvation. J Plant Physiol 160:311-319

Oleksyn J, Tioelker MG, Lorenc-Plucińska G, Konwińska A, Żydkowiak R, Karoleski P, Reich PB (1997) Needle $\mathrm{CO}_{2}$ exchange structure and defense traits in relation to needle age in Pinus heldreichii Christ - a relict of Tertiary Flora. Trees 12:82-89

Pinheiro C, Rodrigues AP, de Carvalho IS, Chaves MM, Ricardo CP (2005) Sugar metabolism in developing lupin seeds is affected by a short-term water deficit. J Exp Bot 56:2705-2712

Ratajczak W (1986) Asparagine metabolism in developing seeds of Lupinus luteus L. Biochem Physiol Pfl 181:17-22

Ratajczak W, Gwóźdź EA, Ratajczak L (1988) Effects of asparagine and methionine on storage protein synthesis in cultured lupin cotyledons. Acta Physiol Plant 10:143-149

Ratajczak W, Gwóźdź EA, Miądowicz M (1996) Effects of nitrogen nutrition on storage protein composition yellow lupin cotyledons cultured in vitro. Acta Physiol Plant 18:295-304 
Ratajczak W, Borek S, Podgórski A, Ratajczak L (1999) Variability of globulin composition in cultivars and individually tested seeds of yellow lupin (Lupinus luteus L.). Acta Physiol Plant 21:413-417

Smeekens S, Jingkun M, Johannes H, Rolland F (2010) Sugar signals and molecular networks controlling plant growth. Curr Opin Plant Biol 13:274-279

Spurr AR (1969) A low viscosity epoxy resin embedding medium for electron microscopy. J Ultrastruct Res 26:31-43

Weber H, Borisjuk L, Heim U, Sauer N, Wobus U (1997) A role for sugar transporters during seed development: molecular characterization of a hexose and a sucrose carrier in fava bean seeds. Plant Cell 9:895-908

Weber H, Borisjuk L, Wobus U (2005) Molecular physiology of legume seed development. Annu Rev Plant Biol 56:253-279

Wilcox JR, Shibles RM (2001) Interrelationships among seed quality attributes in soybean. Crop Sci 41:11-14

Woźny A, Młodzianowski F, Stefaniak B (1984) Protein bodies formation in yellow lupin seeds. Acta Soc Bot Pol 53:3-9 